\title{
Frequency of Depression and Anxiety among Tuberculosis Patients
}

\author{
Amreen', Nadeem Rizvi2 \\ ${ }^{1}$ Department of Psychology, University of Karachi, Karachi, Pakistan \\ ${ }^{2}$ Department of Chest Medicine, Jinnah Postgraduate Medical Centre, Karachi, Pakistan \\ Email: rizvi_n@hotmail.com
}

How to cite this paper: Amreen and Rizvi, N. (2016) Frequency of Depression and Anxiety among Tuberculosis Patients. Journal of Tuberculosis Research, 4, 183-190. http://dx.doi.org/10.4236/jtr.2016.44021

Received: November 18, 2016 Accepted: December 12, 2016

Published: December 15, 2016

Copyright $\odot 2016$ by authors and Scientific Research Publishing Inc. This work is licensed under the Creative Commons Attribution International License (CC BY 4.0).

http://creativecommons.org/licenses/by/4.0/ (c) (i) Open Access

\begin{abstract}
Objective: The aim of present study was to determine the frequency of depression and anxiety among tuberculosis patients. Methods: It was a descriptive study that had investigated the co-morbidity of depression and anxiety among tuberculosis patients with reference to gender. This study was conducted in Jinnah Post Graduate Medical Centre-Chest ward (TB clinic) from July 2014 to September 2014. Hundred diagnosed patients of tuberculosis (50 males and 50 females) were randomly selected. Patient Health Questionnaire (PHQ-9) and Generalized Anxiety Disorder Questionnaire (GAD-7) were used to assess the level of anxiety and depression. Results: Findings indicated that $56 \%$ tuberculosis (TB) patients had moderate to severe level of depression, whereas $65 \%$ TB patients had moderate to severe level of anxiety. Female patients had significantly high prevalence of depression as compared to males $(\mathrm{t}$ $=-2.173, \mathrm{P}<0.05)$. Similarly, prevalence of anxiety was also significantly higher in female patients $(t=-3.468, P<0.05)$. Conclusion: Likelihood of depression and anxiety was frequent in tuberculosis patients. However, better management of these psychiatric morbidities may improve treatment adherence, illness perception and patient coping skills.
\end{abstract}

\section{Keywords}

Tuberculosis, Depression, Anxiety, Patient Health Questionnaire, Generalized Anxiety Disorder Questionnaire

\section{Introduction}

Tuberculosis is considered to be one of the most globally deadliest and transmissible diseases. It is a chronic infectious disease caused by mycobacterium tuberculosis. According to WHO report 2014 disease statistics, tuberculosis is the second leading cause 
of death among infectious disease [1].

The WHO's stop TB strategy is comprised of following outstanding Directly Observed Therapy (DOTS) advancement and improvements recommended by WHO [2] [3]. DOTS is a strategy comprised of multiple anti-tuberculosis drugs and lasts for at least 6 to 8 months duration. During the treatment, patient may experience various unpleasant adverse effects due to Anti-Tuberculosis Treatment (ATT) [4].

Pakistan is among the fifth burdened country having tuberculosis so prevalent (approximately 61\%). That's why National TB Program (NTP) has established many TB diagnostic and treatment centers all over the Pakistan for the early diagnosis and programmatic management of TB. The doctors and the paramedical staff are regularly trained to provide better care for TB patients. Moreover, screening and treatment are offered free of cost through national tuberculosis program. But still various barriers are found regarding its detection and notification. Likewise there are number of patients who are untreated even after its detection due to inadequate knowledge about illness and limited health care resources [5] [6] [7]. Though NTP has reported many successful cases of TB as it is evident from NTP annual report of 2014 that in new registered TB patients the success rate is $93 \%$ [8], further work is needed to improve the quality of treatment and to manage co-morbid factors.

There is growing interest among health professionals regarding the effectiveness of tuberculosis treatment and psychiatric co-morbidity. Several studies have indicated the co-morbidity of depression and anxiety with chronic illnesses especially in tuberculosis. A study conducted in the rural area (Haripur) of Pakistan found $72 \%$ of TB patients had moderate to severe level of depression and anxiety. Moreover, there are certain psychological factors like poor socio-economic condition, lack of social support, reduced quality of life due to TB diagnosis associated with the non-adherence of tuberculosis treatment. However, better management of these co-morbid factors can improve treatment adherence rate [9] [10].

Anxiety and depression are one of the factors that can influence the compliance and well-being of patient [11]. The rationale of this study was to recognize and manage the psychiatric co-morbidity among tuberculosis patients to improve adherence to treatment. That's why it aims to assess the frequency of depression and anxiety in one of the Centre established in tertiary care hospital and to compare it with previously done studies in Pakistan to see if there is any impact of these centers in reducing the level of depression and anxiety.

\section{Methodology}

\subsection{Study Design and Population}

It was a descriptive cross sectional study that aimed to investigate the co-morbidity of depression and anxiety among tuberculosis patients with respect to gender. This study was conducted from July 2014 to September 2014. During this 3 month period twice a week approximately $280 \mathrm{~TB}$ patients got registered for treatment in Chest ward (TB clinic)-JPMC, Karachi, Pakistan. 130 patients met the inclusive criteria of the study 
and 100 patients consented to take part in the study. The total sample size was divided into 2 equal halves based on the gender of patients. Data was randomly collected from 100 diagnosed TB patients of Chest ward (TB clinic) - Jinnah Post Graduate Medical Centre (JPMC), Karachi, Pakistan. Moreover, only diagnosed patients of Tuberculosis were selected irrespective of TB type i.e. Pulmonary TB and extra pulmonary TB. Patients between the age ranges of 18 to 60 years and able to comprehend Urdu language participated in the study. Patients who have completed their ATT or having suspected TB or not willing to participate in study were not selected. Due to low literacy of patients questioners were read for patients and the level of severity was asked for each question and marked respectively.

\subsection{Measures}

Participants were interviewed to fill their demographic information form. To assess the level of patients' depression Urdu translated version of "Patient Health Questionnaire (PHQ-9) [12]" was used. It's a brief scale comprised of 9 items and respondent is asked to rate the occurrence of depression symptoms on 4 point rating scale i.e. "not at all", "several days", "more than half of the days" and "nearly every day". Further, in order to evaluate the anxiety "Generalized Anxiety Disorder (GAD-7) [13]" in Urdu language was used. Scores of 5, 10 and 15 provide the cut points for mild, moderate and severe level of depression and anxiety respectively.

\subsection{Ethical Consideration}

Permission was taken from Institutional Review Board, JPMC to conduct the research in TB clinic of Chest ward OPD Jinnah Post Graduate Medical Centre (JPMC). Data was then collected from the TB patients. All ethical considerations were followed for conducting the research. Informed consent was taken from all participants they had the right to refuse or withdraw from participation any time during administration of questionnaires.

\subsection{Statistical Analysis}

Results were calculated and statistics was applied by using the SPSS (V-19.0). Descriptive statistics was used calculate the demographic information and frequency rate of depression and anxiety. T-test was applied to determine the gender difference for depression and anxiety.

\section{Results}

Data was collected from 100 diagnosed TB patients from Jinnah Postgraduate Medical Centre, Chest ward. It is a well-known tertiary care hospital of Karachi, Pakistan frequently visited by the patients belongs to middle and lower socio-economic category. Participants were equally divided by gender (Male 50\% and females 50\%) and the mean age of total sample was 32.06 . At the time of study $36 \%$ patients were single, $63 \%$ patients were married and $1 \%$ was divorced. Seventy one percent patients were from 
Nuclear and $40 \%$ patients were from joint family set up. They were also interviewed about their TB diagnosis type, 63\% were diagnosed with pulmonary TB and $37 \%$ patients with Extra Pulmonary TB. Moreover, $60 \%$ patients were in intensive phase and $40 \%$ in continuation phase (Table 1 ).

Findings has also indicated that $56 \% \mathrm{~TB}$ patients had moderate to severe level of depression and $65 \%$ TB patients had moderate to severe level of anxiety. Female patients had significantly high frequency of depression as compared to males $(\mathrm{t}=-2.173 \mathrm{df}=$ 98, $\mathrm{P}>0.05)$. Similarly, frequency of anxiety was also significantly higher in female patients $(\mathrm{t}=-3.468, \mathrm{df}=98, \mathrm{P}>0.05)$.

\section{Discussion}

In recent year there has been growing concern to identify and manage psychiatric co-morbidity among tuberculosis (TB) patients. This study focused on TB patients during treatment when they receive multiple drugs for limited period of time usually from 6 to 8 months. The overall frequency of depression and anxiety was 56\% and $65 \%$ respectively which is higher as compared to (depression $46 \%$ and anxiety $47 \%$ ) study conducted at JPMC in 2008 [14]. Moreover, the overall frequency of depression and anxiety in TB patients was much higher than the community based population of $\mathrm{Pa}$ kistan i.e. 34\% (range 29\% - 66\% for females and 10\% - 33\% for males) [15] (Table 2).

Present study results are consistent with the research conducted in the rural areas of Pakistan and found moderate to severe level of depression and anxiety among pulmonary TB patients [9]. The relationship between tuberculosis and mental health is complex. Many psychiatric disorders are positively linked with the high risk of tuberculosis and with poorer adherence to anti-TB treatment. On the other hand, diagnosis of tuberculosis increases risk of psychiatric complication and social isolation [16]. Various studies have indicated that Patient with tuberculosis report several psychiatric disorders like depression, anxiety and somatoform symptoms. Further, there are certain psychosocial factors which are associated with TB like frequent smoking, increased alcohol

Table 1. Demographic characteristics of sample.

\begin{tabular}{ccc}
\hline $\mathbf{N}=\mathbf{1 0 0}$ & Percentage & Mean Age \\
\hline \multirow{2}{*}{ Gender } & Male $=50 \%$ & $\mathbf{3 5 . 8 6}$ \\
& Female $=50 \%$ & $\mathbf{2 8 . 4 6}$ \\
Marital Status & Single $=36.0 \%$ & 21.06 \\
& Married $=63.0 \%$ & $\mathbf{3 8 . 0 6}$ \\
& Divorced $=1.0 \%$ & 60.00 \\
Family System & Nuclear $=71 \%$ & 31.81 \\
& Joint $=29 \%$ & 32.65 \\
Type of Tuberculosis & Pulmonary $=63 \%$ & 33.79 \\
Treatment Phase & Extra pulmonary $=37 \%$ & 29.10 \\
& Intensive $=60 \%$ & 32.86 \\
& Continuation $=40 \%$ & 30.85
\end{tabular}


Table 2. Severity of Depression and anxiety among Tuberculosis Patients.

\begin{tabular}{ccc}
\hline Level of Severity & N & $\%$ \\
\hline Severity of Depression & 21 & $21.0 \%$ \\
Minimal symptoms & 23 & $23.0 \%$ \\
Mild & 29 & $29.0 \%$ \\
Moderate & 19 & $19.0 \%$ \\
Moderately Severe & 08 & $08.0 \%$ \\
Severe & & \\
Severity of Anxiety & 22 & $22.0 \%$ \\
Minimal Anxiety & 13 & $13.0 \%$ \\
Mild Anxiety & 16 & $16.0 \%$ \\
Moderate Anxiety & 49 & $49.0 \%$ \\
Severe Anxiety & &
\end{tabular}

consumption, divorce, and isolation from the family [16] [17] [18] [19] [20].

Psychiatric co-morbidity seems to be an important associated factor in treatment outcome of patients suffering from TB. Psychopathology, specific psychological reactions and complications are highly prevalent in TB patients. These psychological complications are also seen as the adverse effect of anti TB medications [10]. Certain anti tuberculosis drugs like Isoniazid and Ethambutol side effect include mood fluctuation, psychosis, convulsive seizures, mental confusion, dizziness, disorientation etc. [21] [22]. Factors which contribute non adherence response towards anti tuberculosis drugs are an important barrier to control TB. Because it's incomplete treatment or treatment failure may lead to more severe infectiousness, relapse, morbidities and mortality. There are various reasons like prolonged treatment, financial and work related problems, frequent visits to hospital, transportation, low social economic status, slow progression and other illnesses, considered as barrier to treatment adherence [23].

Depression and anxiety prevalence among TB patients was high in females as compared to males (Table 3). High frequency of depression and anxiety in female patients may be due to certain biological factors like hormonal fluctuations associated with menstruation, pregnancy and childbirth. Moreover, there are many social factors like poverty, race, and neighborhood may increase the risk for anxiety and depression in females [24]. Studies conducted in Pakistan have also shown that female sex, middle age, low education level, financial difficulties, being a house wife, and relational problems with husband and in-laws are the associated risk factors of depressive and anxiety disorders [15].

Present research findings emphasize on the importance of routine screening for the symptoms of depression and anxiety in tuberculosis patients. The major limitation of the study was small sample size specifically form JPMC with very limited variables. This study just focused on TB patients, regardless of TB type or severity of illness, no specific 
Table 3. Severity of depression and anxiety with respect to gender.

\begin{tabular}{|c|c|c|c|c|c|c|c|}
\hline \multirow{2}{*}{$\begin{array}{l}\text { Severity of Depression and } \\
\text { gender difference }\end{array}$} & Male & 50 & 9.36 & 7.596 & \multirow{2}{*}{-2.173} & \multirow{2}{*}{98} & \multirow{2}{*}{0.323} \\
\hline & Female & 50 & 12.40 & 6.337 & & & \\
\hline \multirow{2}{*}{$\begin{array}{l}\text { Severity of Anxiety and } \\
\text { gender difference }\end{array}$} & Male & 50 & 9.92 & 6.830 & \multirow{2}{*}{-3.468} & \multirow{2}{*}{98} & \multirow{2}{*}{0.011} \\
\hline & Female & 50 & 14.22 & 5.497 & & & \\
\hline
\end{tabular}

age group, restricted to just people of a socio-economic class and results can't be generalized. In addition the psychiatric diagnosis of the patient was just based on questionnaires rather than structured interviews. A brief counseling session was given to all those patients having moderate to severe level of anxiety. However, further research should aim to identify the psychiatric co morbidities in DOTS and MDR-TB patients and by considering their risk factors and management.

\section{Conclusion}

In conclusion, the frequency of depression (56\%) and anxiety (65\%) among TB patients was high and could be associated with multiple factors like poor socio-economic status, severity of illness, etc. Moreover, it can be concluded that NTPs' clinical advancement has not made any noteworthy difference in patients' well-being. On the basis of revealed finding it is suggested there should be a properly trained psychologist in DOTs as we have in Multi-Drug Resistance (MDR) treatment program [25]. Our doctors and paramedical staff working with TB patients need to modify their approach to recognize and decrease the factors associated with DOTs clinic. However, better management of these psychiatric morbidities may improve treatment adherence and patients' quality of life.

\section{Acknowledgements}

We want to gratefully acknowledge Dr. Rabia Amir (Registrar Medical Officer at JPMC), Dr. Maria Mazhar (TB DOTS Facilitator) and the staff working in DOTS clinic of JPMC Chest ward for their active participation and cooperation throughout the study.

\section{References}

[1] World Health Organization (2016) WHO Global Tuberculosis Report. http://www.who.int/tb/publications/global_report/en/

[2] World Health Organization (2014) Fact Sheet October. http://www.who.int/mediacentre/factsheets/fs104/en/

[3] Moonan, P.K., Quitugua, T.N., Pogoda, J.M., Woo, G., Drewyer, G., Sahbazian, B., et al. (2011) Does Directly Observed Therapy (DOT) Reduce Drug Resistant Tuberculosis? BMC Public Health, 2, 11-19.

[4] Kulkarni, P., Akarte, S., Mankeshwar, R., Bhawalkar, J., Banerjee, A. and Kulkarni, A. (2013) Non-Adherence of New Pulmonary Tuberculosis Patients to Anti-Tuberculosis 
Treatment. Annals of Medical and Health Sciences Research, 3, 67-74.

https://doi.org/10.4103/2141-9248.109507

[5] De Muynck, A., Siddiqi, S., Ghaffar, A. and Sadiq, H. (2001) Tuberculosis Control in Pakistan: Critical Analysis of Its Implementation. Journal of the Pakistan Medical Association, 51, 41-47. http://jpma.org.pk/full_article_text.php?article_id=2497

[6] Fatima, R., Qadeer, E., Enarson, D.A., Creswell, J., Stevens, R.H., Hinderaker, S.G., et al. (2014) Success of Active Tuberculosis Case Detection among High-Risk Groups in Urban Slums in Pakistan. International Journal of Tuberculosis and Lung Disease, 18, 1099-1104. https://doi.org/10.5588/ijtld.14.0001 https://www.ncbi.nlm.nih.gov/pubmed/25189559

[7] Fatima, R., Harris, R.J., Enarson, D.A., Hinderaker, S.G., Qadeer, E., Ali, K., et al. (2014) Estimating Tuberculosis Burden and Case Detection in Pakistan. International Journal of Tuberculosis and Lung Disease, 18, 55-60. https://doi.org/10.5588/ijtld.13.0198

[8] http://ntp.gov.pk/uploads/Annual_Report_2014_NTP_Pakistan.pdf

[9] Aamir, S. and Aisha (2010) Co-Morbid Anxiety and Depression among Pulmonary Tuberculosis Patients. Journal of the College of Physicians and Surgeons Pakistan, 20, 703-704.

[10] Pachi, A., Bratis, D., Moussas, G. and Tselebis, A. (2013) Psychiatric Morbidity and Other Factors Affecting Treatment Adherence in Pulmonary Tuberculosis Patients. Tuberculosis Research and Treatment, 37, Article ID: 489865.

[11] Rubeen, R., Zareen, N., Zameer, S., Rasool, A.G., Naqvi, S.N. and Iqbal, J. (2014) Anxiety and Depression in Tuberculosis Can Create Impact on Quality of Life of Patient. Acta Medical International, 1, 93-98.

[12] Spitzer, R.L., Kroenke, K. and Williams, J.B. (1999) Validation and Utility of a Self-Report Version of PRIME-MD: The PHQ Primary Care Study. JAMA, 282, 1737-1744. https://doi.org/10.1001/jama.282.18.1737

[13] Spitzer, R.L., Kroenke, K., Williams, J.B. and Löwe, B. (2006) A Brief Measure for Assessing Generalized Anxiety Disorder: The GAD-7. Archives of Internal Medicine, 166, 1092-1097. https://doi.org/10.1001/archinte.166.10.1092

[14] Husain, M.O., Dearman, S.P., Chaudhry, I.B., Rizvi, N. and Waheed, W. (2008) The Relationship between Anxiety, Depression and Illness Perception in Tuberculosis Patients in Pakistan. Clinical Practice and Epidemiology in Mental Health, 4, 4. https://doi.org/10.1186/1745-0179-4-4

[15] Mirza, I. and Jenkins, R. (2004) Risk Factors, Prevalence, and Treatment of Anxiety and Depressive Disorders in Pakistan: Systematic Review. BMJ, 328, 794-798.

http://www.ncbi.nlm.nih.gov/pubmed/15070634 https://doi.org/10.1136/bmj.328.7443.794

[16] Araújo, G.S., Pereira, S.M., Santos, D.N., Marinho, J.M., Rodrigues, L.C. and Barreto, M.L. (2014) Common Mental Disorders Associated with Tuberculosis: A Matched Case-Control Study. PLoS ONE, 9, e99551. https://doi.org/10.1371/journal.pone.0099551

[17] Berg, J., Nyamathi, A., Christiani, A., Morisky, D. and Leake, B. (2005) Predictors of Screening Results for Depressive Symptoms among Homeless Adults in Los Angeles with Latent Tuberculosis. Research in Nursing \& Health, 28, 220-229. https://doi.org/10.1002/nur.20074

[18] Duko, B., Gebeyehu, A. and Ayano, G. (2015) Prevalence and Correlates of Depression and Anxiety among Patients with Tuberculosis at Wolaita Sodo University Hospital and Sodo Health Center, Wolaita Sodo, South Ethiopia, Cross Sectional Study. BMC Psychiatry, 15, 214. https://doi.org/10.1186/s12888-015-0598-3 
[19] Wang, J.Y., et al. (2007) The Effect of Smoking on Tuberculosis: Different Patterns and Poorer Outcomes. International Journal of Tuberculosis and Lung Disease, 11, 143-149. https://www.ncbi.nlm.nih.gov/pubmed/17263283

[20] Rehm, J., et al. (2009) The Association between Alcohol Use, Alcohol Use Disorders and Tuberculosis (TB). A Systematic Review. BMC Public Health, 9, 450.

https://doi.org/10.1186/1471-2458-9-450

[21] Arbex, M.A., Varella, M.C.L., Siqueira, H.R. and Mello, F.A.F. (2010) Antituberculosis Drugs: Drug Interactions, Adverse Effects, and Use in Special Situations. Part 2: Second-Line Drugs. Jornal Brasileiro de Pneumologia, 36, 641-656. https://doi.org/10.1590/S1806-37132010000500017

[22] Hsu, C.W., Chu, K.A., Lu, T., Lai, R.S. and Lu, J.Y. (1999) Ethambutol-Induced Psychosis: A Case Report. Chinese Medical Journal ( Taipei), 62, 724-727.

[23] Saqbakken, M., Frich, J.C. and Bjune, G. (2008) Barriers and Enablers in the Management of Tuberculosis Treatment in Addis Ababa, Ethiopia: A Qualitative Study. BMC Public Health, 8, 11. https://doi.org/10.1186/1471-2458-8-11

[24] Watson, K.T., Roberts, N.M. and Saunders, M.R. (2012) Factors Associated with Anxiety and Depression among African American and White Women. ISRN Psychiatry, 2012, Article ID: 432321. https://doi.org/10.5402/2012/432321

[25] NTP National TB Control Program (2012) National Guideline for Programmatic Management of Drug Resistance Tuberculosis (PMDT). 2nd Edition.

Submit or recommend next manuscript to SCIRP and we will provide best service for you:

Accepting pre-submission inquiries through Email, Facebook, LinkedIn, Twitter, etc.

A wide selection of journals (inclusive of 9 subjects, more than 200 journals)

Providing 24-hour high-quality service

User-friendly online submission system

Fair and swift peer-review system

Efficient typesetting and proofreading procedure

Display of the result of downloads and visits, as well as the number of cited articles

Maximum dissemination of your research work

Submit your manuscript at: http://papersubmission.scirp.org/

Or contact jtr@scirp.org 